Perspective

\title{
Genes, brain dynamics and art: the genetic underpinnings of creativity in dancing, musicality and visual arts
}

\author{
Marinos G. Sotiropoulos ${ }^{1}$, Maria Anagnostouli ${ }^{2, *}$ \\ ${ }^{1}$ Department of Neurology, Brigham and Women's Hospital, Harvard Medical School, Boston, MA 02115, USA \\ ${ }^{2}$ Multiple Sclerosis and Demyelinating Diseases Unit \& Immunogenetics Laboratory, 1st Department of Neurology, Medical School, National and \\ Kapodistrian University of Athens, Aeginition University Hospital, 11528 Athens, Greece \\ *Correspondence: managnost@med.uoa.gr (Maria Anagnostouli) \\ DOI:10.31083/j.jin2004110 \\ This is an open access article under the CC BY 4.0 license (https://creativecommons.org/licenses/by/4.0/). \\ Submitted: 13 April 2021 Revised: 18 May 2021 Accepted: 18 August 2021 Published: 30 December 2021
}

Creativity, art and artistic creation in music, dance and visual arts are brain activities specific to humans. Their genetic background remained unexplored for years, but many recent studies have uncovered significant associations with cognition-related genes and loci. These studies are summarized in the present article. Creativity is a trait with heavy genetic influences, which are also associated with mental disorders and altruism. Associated genes include dopaminergic, serotoninergic and other genes (a1-antitrypsin, neuregulin, Brain-derived neurotrophic factor). Music is another complex phenotype with important genetic background. Studies in musicians and their families have highlighted the contribution of loci (e.g., 4q22) and specific genes (vasopressin receptor $1 \alpha$ and serotonin transporter). The latter two are also associated with dancing. Although few studies have investigated visual arts, they appear to be influenced by genetic differences, which could explain the increased prevalence of synesthesia in artists and individuals with autism. Lastly, although genes play an important role in creativity and art, epigenetics and the environment should not be overlooked. The genetic exploration of artistic creativity may provide useful knowledge on cognition, behavior and brain function. It may also enable targeted and personalized art therapy in health and disease. Keywords

Cenetics; Behavior; Cognition; Artists; Psychosis; Creativity; Neuroesthetics

\section{Introduction}

Creativity and artistic creation are inherent components of human nature and, more specifically, human behavior. Art as a human creation is as old as 40,000 BC [1] and evolved in line with human genetic, social and cultural co-evolution [2], with visual art masterpieces occupying museums and musical or dance performances filling theaters and stages worldwide. This universal phenomenon of art and artistic creativity intrigued philosophical thinking from antiquity, with philosophers such as Plato and Aristotle initiating a quest for the meaning of art and esthetics [3]. In the 19th century, interest in the biological roots of this complex human behavior led it from philosophy to psychological experiments, leading to a neuroscientific approach in the latter half of the 20th century, when the neurobiologist Semir Zeki identified distinct brain areas involved in perceiving visual elements, such as form, color and movement, as well as beauty [3]. In 1994, in the middle of the "Decade of the Brain" (1990-2000), he introduced the term neuroesthetics [3], positing that, since esthetics and artistic expression are a product of brain function, a theory of esthetics needs to have a neurobiological basis [4]. In discussing the substrate of this neurobiological basis, we are certainly guided towards behavioral neurochemistry and the human genome.

This progress was made possible due to technological achievements in imaging and genetics. Functional neuroimaging, initially using electroencephalography, Positron Emission Tomography, magnetoencephalography and, more recently, functional Magnetic Resonance-Imaging (fMRI), can identify brain regions activated during cognitive activity or behavior. These techniques, along with advanced, large-scale genetic and genomic analytical methods such as Genome-Wide Association Studies (GWAS), have paved the way to unique discoveries in neurology, psychiatry and cognitive neuroscience. These techniques can elucidate the missing links between the phenotype of creativity and artistic expression, the endophenotype of brain circuitry, and the human genome [5].

The neuroanatomy and neurochemistry of creativity are complex, and creation is rooted in spatiotemporal brain dynamics [6]. Genetic, pharmacologic and other experiments have implicated dopaminergic (nigrostriatal and mesocortical), serotonergic and noradrenergic circuits, which affect the cognitive processes of resistance, flexibility and reward [7]. Involved brain areas include the right thalamus, fusiform gyrus and prefrontal cortex [8]. The identification of the genes and loci mediating artistic creation will not only improve our understanding of the mystery of artistry. It will also lead to a more comprehensive understanding of brain dynamics, cognitive functions, behaviors and associated disorders, and the role of art in daily life and various disease states, making evidence-based applications of art-based therapeutic approaches more feasible. 
Prior research in the genetics of cognition and behavior has shown that the association of gene polymorphisms with cognitive processes is challenging, with the results often consisting of weak associations [9]. Creativity is a complex, metacognitive phenomenon, which cannot be simply and robustly accounted for by a small group of genes or brain areas $[10,11]$. Added to that, the elusive nature of art and its multifaceted characters render associations of genes with art-related phenotypes even more difficult. However, many groups have performed studies examining the genetic background of creativity or artistic expression, producing interesting significant associations that can shed light on both brain function and art itself. In this narrative review, we summarize relevant studies examining how genetics underlie brain functions involved in the creation and perception of art.

\section{Methods}

Relevant published scientific articles were searched on the Medline database via PubMed and Embase until May 2021, using the following combination of terms: (gene OR genes OR genetic* OR polymorphism) AND (creativity OR artist) AND brain. Potentially eligible studies spanned from 1968 to 2021. No restrictions on language and publication year were applied. Reference lists of the included studies and relevant reviews were additionally hand-searched for potentially eligible studies (snowball method). The authors summarize the results of genetic linkage and association studies in Tables $1,2,3$.

\section{Creativity, mental illness and art}

"A writer is someone who has taught his mind to misbehave."

\section{-Oscar Wilde}

Creativity is the ability to produce work that is original and novel, but at the same time meaningful and useful [12]. It is an attribute of the human brain that contributes to its adaptability and differentiates it from other animals [5]. Creativity can guide the creation of art or find an expression in different professional and social fields, including biomedical research [13]. In all of its expressions, creativity entails the ability to perceive incoming signals and devise seemingly random combinations between them, generating novel, meaningful ideas [14]. This was recently demonstrated in a study employing both electroencephalographic monitoring and transcranial alternating current stimulation: alpha oscillations in the right temporal lobe were associated with the ability to suppress obvious associations to allow the drawing of remote connections, and thus engage in the abstract thinking required in a creative process [15].

The twin study is a key methodology in behavioral genetics: it compares the similarity of different traits between monozygotic (identical) with dizygotic (nonidentical) twins to reveal the importance of environmental and genetic influences. Twin studies, both in 4-year-old British twins and 18-77-year-old US twins reared apart, have shown that ap- plied creativity and figure drawing have heavy genetic influences, sometimes greater than the environmental effect $[16,17]$. In toddlers, performance in divergent thinking tests is moderately to highly correlated to the parents' performance, demonstrating that, from early neurodevelopmental stages, the background for creativity is present, either due to genetic influences or the impact of social learning [18]. A common genetic substrate has also been proposed for homosexuality and creativity in theater and writing, as this association was found in Swedish twins [19]. Convergent thinking, the ability to make associations between concepts, is another important but overlooked component of the creative process.

Interestingly, the genetic background appears to differ between convergent and divergent thinking. Whereas in a study of Chinese college students, divergent thinking was associated with KATNAL2 polymorphisms, convergent thinking was associated with polymorphisms in Catechol-O-methyltransferase (COMT) and Synaptosomal nerve-associated protein 25 (SNAP-25), which in turn have been implicated in neuroplasticity and cognition [20]. This points to convergent and divergent thinking as two distinct creative processes, not two extremes of one common process. Besides a different genetic background, differences between convergent and divergent thinkers can be observed in the underlying memory processing, personality, and neurochemistry (involving noradrenergic and dopaminergic pathways, respectively) [21].

Since antiquity, creativity has been associated with mental disorders, even with inappropriate terms such as "mad genius" [22]. This appears to be a true association, as patients with schizophrenia or bipolar disorder exhibit high creativity and may work in more artistic and creative professions, respectively, whereas, according to registry studies, their siblings are also more likely to have a creative occupation, working as designers, scientists, artists, musicians or authors [2224]. A polygenic risk score analysis showed that the genetic risk for schizophrenia and bipolar disorder could predict a creative occupation regardless of familial relations, implicating that these disorders share a genetic background with creative employment [23]. The heritability of working in a creative profession, such as architecture, art teaching, design, curating, writing, reporting or performing, has been calculated at $70 \%$, pointing to a strong genetic influence [25]. The preservation of genetic polymorphisms related to mental disorders in the gene pool could signify they also carry positive effects, namely creativity and altruism [26, 27]. Genes participating in this shared vulnerability model include Taq1A, DRD2, COMT, 5-HTR2A, SCL6A4 and TPH1 [28]. As described above, these genes participate in dopaminergic and serotoninergic pathways and convergent thinking, which are all associated with creativity. Underlying endophenotypes include decreased latent inhibition and increased noveltyseeking [28]. Attention deficit-hyperactivity disorder is also associated with higher creative achievement [29]. In contrast, COMT polymorphisms play a role in increased brain 
connectivity within and between the default mode and dorsal attention networks in children with the disorder [30].

The dopaminergic system appears to be at the forefront of creativity association studies due to its role in creative thought and behavior [31]. It has been proposed that striatal dopamine allows flexibility, whereas prefrontal dopamine is associated with persistence, with changes in this fine balance accounting for both creativity and psychiatric disorders [32]. Parkinson's disease has also been associated with increased creativity, preoccupation with art and artistic output, either due to dopaminergic treatment or directly due to damage in the nigrostriatal, prefrontal and mesolimbic pathways [33]. A groundbreaking pilot study in 2006 found significant associations of creativity with the A1 allele of the D2 dopamine receptor (DRD2) gene locus, which, combined with a serotonergic gene locus, could account for $9 \%$ of the variance in creativity between subjects [34]. Performance in divergent thinking tests is negatively associated with D2 receptor density in the thalamus [31]. This lower firing threshold could reduce the filtering capacity of the thalamus and thus increase information flow and pre-frontal cortical excitation, possibly resulting in wide associations and stimulus perceptions, but also a higher liability for psychotic disorders. A common finding in these studies is that creativity is unrelated to intelligence $[31,34]$.

Another study associated DRD2 with emotional intelligence, which increased divergent thinking, particularly in female subjects [35]. Besides DRD2, the D4 dopamine receptor gene has also been studied as a candidate "creativity gene". Another study found an association of the 7-repeat allele with low levels of divergent thinking, as well as low flexibility and impulsivity [36]. Additionally, subjects with the 5repeat $D R D 4$ allele have higher impulsivity, lower focus, and thus higher creativity levels on testing [9]. They also exhibit higher mean diffusivity in the cortex and subcortical areas on functional imaging, possibly signifying that creative individuals are inattentive and cannot suppress irrelevant information. Zabelina et al. [11] confirm the importance of dopaminergic genes for creativity, namely the Dopamine transporter in the striatum and COMT in the PFC, contradicting Reuter et al. [34] who found no association with COMT. COMT polymorphisms have also been associated with insight problem solving (i.e., the "aha" moment when realizing a solution to a problem) [37]. The importance of COMT in both dopamine and norepinephrine metabolism also reinforces the importance of norepinephrine in creative cognition, although other noradrenergic "creative" genes have not been identified $[7,21]$.

The serotonergic system is related to memory, cognition and mood, and has projections in the prefrontal cortex [38]. One study associated polymorphisms in the serotonin transporter, encoded by SLC6A4, with verbal and figural creative ability (creating sentences and pictures, respectively): the 5HTTLPR short/short haplotype, leading to decreased expression, thus higher serotonin availability, was significantly associated with more original ideas [38]. Additionally, the A allele of Tryptophan hydroxylase 1, a gene participating in serotonin synthesis, is significantly associated with creativity and, together with the DRD2 dopamine receptor gene described above, has been found to account for $9 \%$ of the variance in creativity [34]. It has been proposed that the two systems interact, with dopamine being more involved in left hemisphere functions (verbal creativity). At the same time, serotonin acts more in the right hemisphere (figural and numeric creativity) [34].

Genes outside these neurotransmitter families have also been associated with creativity. Interestingly, silent carriers of alpha-1 antitrypsin mutations, who do not exhibit pulmonary emphysema or liver disease, are significantly more likely to have an "intense creative energy" phenotype, and to be creative artists, working in music, dancing, visual arts, writing, photography or acting, whether professionally or not [39]. They also exhibit higher anxiety, bipolar disorder and post-traumatic stress disorder $[39,40]$. This has been associated with alpha-1 antitrypsin's role in inflammation, copper homeostasis and neurodevelopment [40]. It has also been proposed that these individuals exhibit higher signal flow in subcortical circuits [40]. A polymorphism in the neuregulin 1 promoter is also associated with higher creativity in individuals with high Intelligence Quotients [26]. This gene is also related to PFC activation and has been linked to psychosis, affecting neuronal development, neuroplasticity and the glutamatergic system [26].

Interestingly, a study found that patients with bipolar disorder in the manic phase only exhibited higher creativity if they had a high-functioning allele in the BDNF gene. In contrast, this effect was not present in patients without mania or healthy controls and is possibly related to an increase in dopaminergic activity [41]. BDNF is involved in neurogenesis, memory and cognition and implicated in depression and bipolar disorder. Creative cognition also correlates with plasma oxytocin levels, and single nucleotide polymorphisms in the oxytocin receptor gene can predict creative imagination and other creative traits. Oxytocin decreases anxiety and potentiates dopaminergic stimulation. Interestingly, intranasal administration can increase creativity but decrease analytical reasoning [42, 43].

Published in 2018, the first genome-wide association study on creativity employed whole-genome analysis and fMRI whole-brain connectivity measures in fMRI to identify genes and circuits underlying figural creativity [44]. The model combining the two approaches (neural and genetic) could predict creativity at a rate of $78.4 \%$. The results validated the importance of genes in creativity (genetic data yielded predictability of $77.5 \%$ ) and uncovered the importance of new neurotransmitter systems, pointing to glutamatergic and GABAergic genes, as well as strong top-down control networks and weak bottom-up sensory processes (contradicting previous studies [9, 31, 40], Table 1, Ref. $[9,11,20,26,31,34-36,38,40,41])$, and areas such as the vi- 
Table 1. Summary of published studies examining the genetic background of creativity.

\begin{tabular}{|c|c|c|c|c|c|}
\hline \multicolumn{6}{|c|}{ Creativity } \\
\hline Study type & Outcome or phenotype measured & Gene or locus associated & $\begin{array}{c}\text { Neurotransmitter/process } \\
\text { involved }\end{array}$ & Country & Reference \\
\hline Association & creativity tests & DRD2, TPH1 & dopamine, serotonin & Germany & {$[34]$} \\
\hline Association & artistic occupation or vocation & alpha-1 antitrypsin & $\begin{array}{l}\text { neurodevelopment, } \\
\text { inflammation, copper }\end{array}$ & USA & {$[40]$} \\
\hline Association & creativity tests (verbal and figural) & SLC6A4 (serotonin transporter) & serotonin & Russia & [38] \\
\hline Association & self-reported creativity & neuregulin 1 & $\begin{array}{l}\text { neurodevelopment, } \\
\text { neuroplasticity, glutamate }\end{array}$ & Hungary & {$[26]$} \\
\hline $\mathrm{PET} / \mathrm{MRI}$ & divergent thinking test & DRD2 & dopamine & Sweden & {$[31]$} \\
\hline Association & creativity tests (in patients with mania) & $B D N F$ & dopamine & Brazil & [41] \\
\hline Association & divergent thinking test & DRD4 & dopamine & Israel & {$[36]$} \\
\hline Association & $\begin{array}{c}\text { emotional intelligence, divergent thinking } \\
\text { test }\end{array}$ & DRD2 & dopamine & Japan & [35] \\
\hline Association & divergent thinking test, DTI & DRD4 & dopamine & Japan & [9] \\
\hline Association & $\begin{array}{l}\text { divergent thinking test, real-world creative } \\
\text { achievement }\end{array}$ & dopamine transporter, COMT & dopamine & USA & {$[11]$} \\
\hline Genome-wide association & figural creativity tests & GABRG3, SHANK2, FGF12 & glutamate, GABA & China & {$[44]$} \\
\hline Association & divergent and convergent thinking tests & KATNAL and COMT, respectively & $\begin{array}{l}\text { microtubule function, } \\
\text { dopamine respectively }\end{array}$ & China & {$[20]$} \\
\hline
\end{tabular}

sual association cortex and areas near Broca's and Wernicke's areas [44]. A more recent Genome-Wide Association Study of creativity test performance in China found that creativity was a polygenic trait not associated with a single locus, controlled by numerous genes with small effects and showing an overlap with schizophrenia, depression, and risk tolerance and risky behavior [45].

It should be noted that the external validity of divergent thinking tools that are used in most of the studies above is questionable: like all neuropsychologic batteries, creativity tests may not capture the same effects, cognitive processes or endophenotypes as real-world, perceived or subjective creativity. Test scores may even be associated with different dopaminergic circuits than real-world creativity [11], and genetic associations may also be different [46]. As a result, the findings discussed here (summarized in Table 1) should be interpreted with caution, as the generalizability of test performance to real-life traits is not perfect.

\section{Dancing to the tune of serotonin and vasopressin?}

"Dance is the hidden language of the soul."

\section{-Martha Graham}

The phenotype of a good dancer is complex, entailing a wide range of mental abilities, including music perception, coordination, creativity and physical competence. An association study in dancers, athletes and subjects who were neither dancers nor athletes revealed a significant association of dancing with polymorphisms of the arginine vasopressin $1 \mathrm{a}$ receptor (AVPR1a) and the serotonin transporter (SLC6A4) genes. The dancers' characteristics associated with the haplotypes included spirituality, altered consciousness, social contact and communication. Using a robust family-based test, the authors validated this association (Table 2, Ref. [47-56]) [47].

Also called arginine vasopressin and antidiuretic hormone, vasopressin is important in higher cognitive functions [50]. Vasopressin -particularly the AVPR1a genotypehas also been associated with affiliative behavior, courtship and social communication [47]. The human serotonin transporter gene (SLC6A4; 5-HTT) is expressed in the brain, particularly in areas participating in emotion [50]. Serotonin has been associated with spiritual experiences, which often incorporate dancing. It is hypothesized that decreased SLC6A4 promoter function, which results in higher serotonin levels, could result in higher creativity and attention to music. Another possible association was with the dopamine D4 receptor (DRD4) [47].

Interestingly, SLC6A4 polymorphisms also modulate cognitive flexibility under psychosocial stress, such as a public performance [57]. Although these initial associations are revealing, they cannot adequately to explain the wide differences in dancing abilities between people, which could be affected by numerous other genes, epigenetic changes and other environmental effects. Dancing is a complex phenotype whose background warrants further exploration with well-designed genetic and genomic studies including subjects with diverse, well-documented relationships with dance: different training, culture, perceived talent or ability, dance types, musical training, dancing solo, with a partner or in a group etc. 
Table 2. Summary of published studies examining the genetic background of musicality and dancing.

\begin{tabular}{|c|c|c|c|c|c|}
\hline \multicolumn{6}{|c|}{ Music and dancing } \\
\hline Study type & Outcome or phenotype measured & Gene or locus associated & Neurotransmitter/process involved & Country & Reference \\
\hline Association & professional dance & AVPR1a, SLC6A4 & vasopressin, serotonin & Israel & {$[47]$} \\
\hline Linkage & music perception tests & $4 q 22,8 q 13-q 21$ & neurogenesis, inner ear transduction & Finland & {$[48]$} \\
\hline Genome-wide linkage & absolute pitch & $\begin{array}{c}8 \mathrm{q} 24.21,7 \mathrm{q} 22.3,8 \mathrm{q} 21.11 \\
9 \mathrm{p} 21.3\end{array}$ & unknown, possibly adenylate cyclase & USA & {$[49]$} \\
\hline Association & music perception tests & AVPR1a, SLC6A4, TPH1 & vasopressin, serotonin & Finland & {$[50]$} \\
\hline Association & active music listening & AVPR1a (vasopressin receptor) & vasopressin & Finland & {$[51]$} \\
\hline $\begin{array}{l}\text { Genome-wide linkage } \\
\text { and association }\end{array}$ & pitch-production accuracy test & 4q23, UGT8 & myelin lipid synthesis and clearance & Mongolia & {$[52]$} \\
\hline Association & choir participation & SLC6A4 (serotonin transporter) & serotonin & UK & {$[53]$} \\
\hline Genome-wide CNV & $\begin{array}{c}\text { music perception tests, self-reported } \\
\text { musical creativity }\end{array}$ & $\begin{array}{c}5 \mathrm{q} 31.1 \text { (protocadherin- } \alpha \text { ), 2p22 } \\
\text { (GALM), 8q24 }\end{array}$ & $\begin{array}{l}\text { neurodevelopment, serotonin, } \\
\text { synaptic function }\end{array}$ & Finland & {$[54]$} \\
\hline Genome-wide linkage & music perception tests & $\begin{array}{l}\text { 3q21.3 (GATA2), 4p14 } \\
\text { (protocadherin 7) }\end{array}$ & $\begin{array}{l}\text { auditory pathway development, } \\
\text { cochlea, amygdala }\end{array}$ & Finland & {$[55]$} \\
\hline Genome-wide linkage & $\begin{array}{l}\text { arranging and composing music, } \\
\text { non-musical creativity }\end{array}$ & $\begin{array}{c}\text { 16p12.1-q12.1, 4q22.1 } \\
\text { Xp11.23, 18q21 }\end{array}$ & $\begin{array}{c}\text { cerebellar LTD, hearing, } \\
\text { synaptogenesis, neurogenesis }\end{array}$ & Finland & {$[56]$} \\
\hline
\end{tabular}

\section{Is musical expression based on gene expression?}

"It really is a very odd business that all of us, to varying degrees, have music in our heads."

\section{-Oliver Sacks, Musicophilia: Tales of Music and the Brain}

It is common knowledge that musical talent is not equally distributed among all individuals [58]. Certain "musical" families, such as the Bach family, which produced over 50 prominent musicians over 200 years, dominate music history. While cultural factors, exposure to music and professional or amateur training are all important environmental determinants of each individual's relationship with music [59], primary evidence has shown that musicality, like other creative attributes, has a biological basis $[54,60]$. An interesting observation is that universal musical rules formed independently in different cultures that did not interact, indicating that these rules were determined by the organization of the human brain rather than cultural factors [48]. These musical rules, guided by neural, genetic, cognitive or even mathematic principles, were not known to the first human creators of music, and were only studied, understood and defined retrospectively by scholars and scientists. In this sense, the cognitive functions underlying music closely resemble language $[60,61]$.

Although music is also a very complex phenotype, its two extreme forms have a clear definition and exhibit significant heritability (Table 2). Congenital amusia (tone deafness), where subjects cannot recognize melodies and out-of-keynotes while their rhythm perception is intact, is a familial condition, appearing in 39\% of first-degree relatives of affected individuals compared to $3 \%$ in the general population [62]. In general, perceiving pitch has a heritability of 71$80 \%$, while the shared environment within families does not significantly affect pitch perception [63]. On the other end of the spectrum, absolute pitch (AP), the ability to name a pitch without a reference, also has a genetic component [64], which has been localized to $8 \mathrm{q} 24.21$ and, less robustly, to 7q22.3, 8q21.11, and 9p21.3 [49]. Interestingly, a study has identified a phenotypic and genetic overlap between AP and synesthesia. These two "artistic extreme" cognitive phenotypes tend to coexist in individuals and share a linkage with chromosomes $6 \mathrm{p}$ and 2 , possibly pointing to a common neurodevelopmental background [65].

A research group from Finland has been performing genetic analyses in a cohort of families of musicians and nonmusicians, using music perception tests that minimize the effect of training and culture (Table 2) [48]. Initially, they demonstrated a substantial heritability of $47 \%$ in combined test performance. Linkage analysis showed significant linkage on $4 \mathrm{q} 22$, which contains the netrin receptor UNC5C (important during neurogenesis), and suggestive linkage on 8q13-q21. This area contains the TRPA1 gene (transient receptor potential ankyrin 1, possibly a transduction channel in inner ear hair cells) [48]. A research group in Mongolia also corroborated the importance of this locus in their population, finding a linkage for musicality at $4 \mathrm{q} 23$, with an overlapping supporting interval [52]. This finding confirms that, while music and the corresponding musical phenotype varies significantly across different cultures, musicality is an inherent human trait with common genetic roots regardless of cultural expression.

Besides test performance, self-reported creativity and musicality are also associated with copy number variations in loci containing genes involved in neurodevelopment, serotonin metabolism, learning, memory, synaptic function and schizophrenia (e.g., galactose mutarotase, protocadherin-a 1-9, МСТР2) [54]. 
The serotonin and vasopressin systems appear to be involved in various aspects of the musical phenotype. Besides playing an instrument, composing, improvising or arranging are different cerebral functions associated with activation in prefrontal, sensory and motor areas and deactivation of limbic areas [66]. Genetic determinants have been found in this population as well, with self-reported musical creation correlating with test performance, which in turn was strongly associated with AVPR1A haplotypes (RS1 and RS3), and weakly with SCL6A4 polymorphisms (variable number tandem repeat). These are the same polymorphisms found in dancers and are involved in social and affective behavior [47]. Significant differences in AVPR1 haplotypes have also been found in individuals who actively listen to music [51]. SLC6A4 has been associated with choir participation [53], while both genes have also been associated with memory [67]. Interestingly, administration of intranasal vasopressin was shown to improve participants' mood, increase alertness and decrease working memory for musical tasks only in a complex fashion [68].

However, a genome-wide linkage analysis performed in a larger sample in the Finland cohort yielded lower heritability estimates, between 23 and 34\% for composing and arranging and only $11 \%$ for improvising [56]. Concerning arranging, the analysis revealed a significant linkage with an area containing the GSG1L AMPA receptor gene, which is important in cerebellar long-term depression and hearing. The cerebellum - and its synaptic plasticity- has previously been associated with musical ability, improvisation and rhythm working memory. It also revealed a suggestive link with an area near the MYCN gene, mutations of which cause Feingold syndrome type 1 (microcephaly, intellectual disability, digital malformations and deafness) [56]. Composing was linked to 4q22.1, containing the netrin receptor UNC5C, which is implicated in neurodevelopment, and UGT8, which had also been found in Mongolian musical families [52]. The "neither composing nor arranging" phenotype was linked to an area previously associated with cognition, which contains the cadherin genes associated with schizophrenia. Finally, non-musical creativity was linked to an area containing several genes involved in synaptogenesis and neurogenesis (synapsin 1), as well as the memory, reward and emotion systems (ELK1, KCND1 and SYP) [56].

Besides executive mental functions, a GWAS on the same cohort focused on the sensory, auditory component of music perception. The strongest linkage was found near the GATA binding protein 2(GATA2) gene, which regulates the development of cochlear hair cells and the inferior colliculi, which are important in a tonotopic organization. Another region linked to music perception contained the protocadherin 7 genes, which have been linked to the function of the cochlea and the amygdala. Regions of the absolute pitch were not present in the linkage, indicating that AP is a cerebral "gift" rather than an auditory property [55].
The limitations of most published studies are the small sample sizes and the possibly low accuracy of self-reporting or standardized testing, which may not perfectly capture realworld ability [69]. However, the findings remain significant and provide useful insights into the genetics of musicality. Although most of the findings stem from the same cohort in Finland, other cohorts from the UK and Mongolia seem to validate the involvement of these genes and loci. Musicality is not only genetically determined, and the interactions between genetic and environmental components, such as growing up in a musical environment and receiving professional training, are also worth exploring [70]. The importance of environmental exposure is discussed in Section 7.

\section{Visual arts and synesthesia}

"It took me four years to paint like Raphael, but a lifetime to paint like a child."

\section{-Pablo Picasso}

Besides performing arts, visual arts are also important components of artistic creation. Using magnetoencephalographic and functional MRI studies, Semir Zeki has studied the neuroanatomy behind viewing forms, colors, faces and moving objects, uncovering a parallel processing system, whereby each stimulus is individually processed in a dedicated area of the visual cortex $[71,72]$. Interestingly, if it exists, the neuroanatomical substrate that mediates the integration of all these attributes (form, color, movement) into a whole (e.g., a painting) has not been discovered yet.

Patients with Parkinson's disease exhibit increased interest in visual arts, either producing or admiring it. Although the dopaminergic disruption may be important, the precise physiological and neurochemical correlations of this nuanced behavioral change have not been identified [33]. In certain studies discussed above, such as in the British and US studies in monozygotic or dizygotic twins, children and adults, applied creativity was tested by asking the participants to draw human figures or houses. Creative talent in these drawings carried a heavy genetic component, sometimes greater than the environmental effect $[16,17]$. However, very few studies have associated visual arts with specific genes or loci. As discussed above, silent alpha-1 antitrypsin mutation carriers are more likely to be creative and work in visual arts or photography [39]. In the genome-wide association study on creativity discussed before, the phenotype measured was figural creativity, which had a heavy genetic component associated with areas such as the visual association cortex and areas near Broca's and Wernicke's areas [44].

Synesthesia, where stimulation of one sensory or cognitive pathway (e.g., letters or sounds) is associated with experiences in a second pathway (e.g., colors), is a heritable, polygenic phenomenon present in $2-4 \%$ of the population $[73,74]$. As a different way of "seeing the world", it has been hypothesized to "predispose" to artistic creation and is indeed more frequent in art students [75]. Synesthesia, in particular seeing colors when listening to sounds, appears to have a 
Table 3. Summary of published studies examining the genetic background of synesthesia.

\begin{tabular}{|c|c|c|c|c|c|}
\hline \multicolumn{6}{|c|}{ Synesthesia } \\
\hline Study type & $\begin{array}{l}\text { Outcome or phenotype } \\
\text { measured }\end{array}$ & Gene or locus associated & $\begin{array}{c}\text { Neurotransmitter/process } \\
\text { involved }\end{array}$ & Country & Reference \\
\hline Genome-wide linkage & sound-color synesthesia & $2 \mathrm{q} 24,5 \mathrm{q} 33,6 \mathrm{p} 12,12 \mathrm{p} 12$ & $\begin{array}{c}\text { neurodevelopment, } \\
\text { neuroplasticity autism }\end{array}$ & UK & {$[76]$} \\
\hline Association & sound-color synesthesia & $\begin{array}{c}\text { COL4A1, ITGA2, MYO10, ROE } \\
\text { and SLIT2 }\end{array}$ & C9A6, axonogenesis & Netherlands & {$[77]$} \\
\hline
\end{tabular}

genetic component. A linkage study found a significant linkage with chromosome 2q24 and suggestive linkage with other areas $(5 q 33,6 \mathrm{p} 12$, and 12p12) [76]. An association study for the same trait found associations with genes involved in the process of axonogenesis (SLIT2, MYO10, ROBO3, ITGA2, COL4A1, and SLC9A6), whereby a disruption could result in atypical, increased structural and functional neural connections between different cortical areas, leading to synesthesia (Table 3, Ref. [76, 77]) [77, 78]. According to some studies, synesthesia may genetically overlap with schizophrenia and absolute pitch, the latter relationship localizing to chromosomes $6 \mathrm{q}$ and $2[65,79]$.

Interestingly, synesthesia is more prevalent in patients with autism with savant traits [80]. Latent savant-like skills can be uncovered in healthy individuals without autism or savant traits by suppressing left frontotemporal lobe activity, indicating that the dynamics for such cognitive functionality exist in all brains but are suppressed [81]. Children with autism, who have no significant environmental exposure to art, but can create magnificent works of art, are especially thought-provoking examples of the cerebral and genetic determinants of artistic creativity. A characteristic example is Iris Grace Halmshaw, a British artist with autism who started painting at age 5: her paintings not only allowed her to communicate her thoughts and emotions but are also coveted by art galleries worldwide for their immense artistic value.

\section{Not just genes}

Creativity and artistry are multifaceted traits, determined by multiple components of behavior and personality, each having its own genetic and environmental determinants. Although this work attempted to concentrate the available evidence on the genetic differences in artistic individuals, it is clear that environmental factors are also important. For instance, psychological factors such as birth order or exposure to an artistic household can affect artistic expression, creativity, and even mental illness [82]. Identifying these factors is important since they can be modified with appropriate interventions [83]. For example, a recent study showed that DRD2 and COMT polymorphisms interact with the parenting style the individual was exposed to, such as mother authoritativeness, to explain variance in creativity. More specifically, a high genetic susceptibility ("creative genes") leads to a greater environmental susceptibility (being more or less creative depending on positive or negative parenting) in an interesting genetic-environmental interaction [84].
In exploring the effect of environmental factors, epigenetics may prove to be an important connecting link. Although there have been no studies on the epigenetics correlating with creativity and artistic cognition, it has been hypothesized that the methylation status of the dopamine transporter 1 [85] or the estrogen receptor type $\alpha$ [86] could be associated with creativity and artistic perception [87]. Additionally, epigenetic effects related to Alzheimer's disease may influence artistic output [88], which is known to be affected by the disease [89]. Epigenetics may also underlie the positive effect of art on mental and somatic health [87]. This entire field remains unexplored but could answer many questions about early life experiences, exposure to art, professional training and rehearsing, and their relationship with creative and artistic cognition. Epigenetic inheritance may also play an important role and should be explored [90].

\section{Conclusions}

From antiquity until now, artistic creativity has been supposed to have significant genetic elements and social and environmental influences. Many genes and genetic loci are associated with creativity or artistry, a subset of them also exhibiting correlations with neurodevelopmental or psychiatric disorders. Further genetic exploration of human artistic creativity will uncover essential knowledge regarding cognition, behavior and general brain functionality, enabling a more targeted and personalized use of art therapy in health and disease.

\section{Abbreviations}

AP, absolute pitch; COMT, Catechol-Omethyltransferase; fMRI, functional Magnetic ResonanceImaging; GWAS, Genome-Wide Association Studies; SBNAP-25, Synaptosomal nerve-associated protein 25; $D R D 2$, D2 dopamine receptor; BDNF, Brain-derived neurotrophic factor; 5-HTT, serotonin transporter gene; TRPA1, transient receptor potential ankyrin 1 .

\section{Author contributions}

MA conceived, guided and supervised the project and provided additional articles. MGS designed the search and conducted the literature review and data extraction. Both authors participated in drafting the manuscript, revised it critically, and approved the final version. 


\section{Ethics approval and consent to participate Not applicable.}

\section{Acknowledgment}

The authors wish to thank once more the Bodossaki Foundation for recording and publishing the lectures of the "Two-day Symposium on Neuroaesthetics" held in Athens, Greece, 29-30 September 2012, on "Bodossaki Lectures on Demand" (blod.gr). During this symposium, senior author Maria Anagnostouli initially presented a lecture with the similar original title "Genes, Brain and Art: Genetic parameters in the expression of talent, imagination and artistic creation" during this symposium. The talk can be accessed at https://www.blod.gr/lectures/gonidia-egkefalos-tehni/.

\section{Funding}

This research received no external funding.

\section{Conflict of interest}

Marinos G. Sotiropoulos has received research support and/or compensation from the World Health Organization, Mallinckrodt Pharmaceuticals and the United States Department of Defense, unrelated to the present work. Maria Anagnostouli has received research and travel-grant support from various pharmaceutical companies engaged in Multiple Sclerosis Therapeutics, unrelated to the present work.

\section{References}

[1] Morriss-Kay GM. The evolution of human artistic creativity. Journal of Anatomy. 2010; 216: 158-176.

[2] Podlipniak P. The Role of Canalization and Plasticity in the Evolution of Musical Creativity. Frontiers in Neuroscience. 2021; 15: 607887.

[3] Anagnostouli M. Neuroaesthetics in the 21st Century: from Plato to Zeki. Athens: self-publication. ISBN: 978-960-93-5337-3. 2014. (In Greek)

[4] Zeki S. Essays on science and society. Artistic creativity and the brain. Science. 2001; 293: 51-52.

[5] Zaidel DW. Creativity, brain, and art: biological and neurological considerations. Frontiers in Human Neuroscience. 2014; 8: 389.

[6] Spivey M. The Continuity of Mind. Oxford University Press: New York. 2006.

[7] Khalil R, Godde B, Karim AA. The Link Between Creativity, Cognition, and Creative Drives and Underlying Neural Mechanisms. Frontiers in Neural Circuits. 2019; 13: 18.

[8] Pidgeon LM, Grealy M, Duffy AHB, Hay L, McTeague C, Vuletic $\mathrm{T}$, et al. Functional neuroimaging of visual creativity: a systematic review and meta-analysis. Brain and Behavior. 2016; 6: e00540.

[9] Takeuchi H, Tomita H, Taki Y, Kikuchi Y, Ono C, Yu Z, et al. Cognitive and neural correlates of the 5-repeat allele of the dopamine $\mathrm{D} 4$ receptor e in a population lacking the 7-repeat allele. NeuroImage. 2015 ; 110: 124-135.

[10] Folley BS, Doop ML, Park S. Psychoses and creativity: is the missing link a biological mechanism related to phospholipids turnover? Prostaglandins, Leukotrienes and Essential Fatty Acids. 2003; 69: 467-476.

[11] Zabelina DL, Colzato L, Beeman M, Hommel B. Dopamine and the Creative Mind: Individual Differences in Creativity are Predicted by Interactions between Dopamine Genes DAT and COMT. PLoS ONE. 2016; 11: e0146768.

[12] Sternberg RJ, Lubart TI. Investing in creativity. American Psychologist. 1996; 51: 677-688.
[13] Goldstein JL. Balzac's Unknown Masterpiece: spotting the next big thing in art and science. Nature Medicine. 2014; 20: $1106-$ 1111.

[14] Goldstein JL. Juxtapositions in Trafalgar Square: tip-offs to creativity in art and science. Nature Medicine. 2013; 19: 1222-1226.

[15] Luft CDB, Zioga I, Thompson NM, Banissy MJ, Bhattacharya J. Right temporal alpha oscillations as a neural mechanism for inhibiting obvious associations. Proceedings of the National Academy of Sciences of the United States of America. 2018; 115: E12144-E12152.

[16] Arden R, Trzaskowski M, Garfield V, Plomin R. Genes influence young children's human figure drawings and their association with intelligence a decade later. Psychological Science. 2014; 25: 1843 1850.

[17] Velázquez JA, Segal NL, Horwitz BN. Genetic and environmental influences on applied creativity: a reared-apart twin study. Personality and Individual Differences. 2015; 75: 141-146.

[18] Hoicka E, Mowat R, Kirkwood J, Kerr T, Carberry M, Bijvoetvan den Berg S. One-Year-Olds Think Creatively, Just Like their Parents. Child Development. 2016; 87: 1099-1105.

[19] Mosing MA, Verweij KJH, Abé C, de Manzano Ö, Ullén F. On the Relationship between Domain-Specific Creative Achievement and Sexual Orientation in Swedish Twins. Archives of Sexual Behavior. 2016; 45: 1799-1806.

[20] Han W, Zhang M, Feng X, Gong G, Peng K, Zhang D. Genetic influences on creativity: an exploration of convergent and divergent thinking. PeerJ. 2018; 6: e5403.

[21] Beversdorf DQ. Neuropsychopharmacological regulation of performance on creativity-related tasks. Current Opinion in Behavioral Sciences. 2019; 27: 55-63.

[22] Keller MC, Visscher PM. Genetic variation links creativity to psychiatric disorders. Nature Neuroscience. 2015; 18: 928-929.

[23] Power RA, Steinberg S, Bjornsdottir G, Rietveld CA, Abdellaoui A, Nivard MM, et al. Polygenic risk scores for schizophrenia and bipolar disorder predict creativity. Nature Neuroscience. 2015; 18: 953-955.

[24] Kyaga S, Lichtenstein P, Boman M, Hultman C, Långström N, Landén M. Creativity and mental disorder: family study of 300,000 people with severe mental disorder. The British Journal of Psychiatry. 2011; 199: 373-379.

[25] Roeling MP, Willemsen G, Boomsma DI. Heritability of Working in a Creative Profession. Behavior Genetics. 2017; 47: 298-304.

[26] Kéri S. Genes for Psychosis and Creativity a promoter polymorphism of the neuregulin 1 gene is related to creativity in people with high intellectual achievement. Psychological Science. 2009; 20: 1070-1073.

[27] Agnati LF, Barlow P, Ghidoni R, Borroto-Escuela DO, Guidolin D, Fuxe K. Possible genetic and epigenetic links between human inner speech, schizophrenia and altruism. Brain Research. 2012; 1476: 38-57.

[28] Carson SH. Creativity and psychopathology: a shared vulnerability model. Canadian Journal of Psychiatry. Canadian Journal of Psychiatry. 2011; 56: 144-153.

[29] Hoogman M, Stolte M, Baas M, Kroesbergen E. Creativity and ADHD: a review of behavioral studies, the effect of psychostimulants and neural underpinnings. Neuroscience and Biobehavioral Reviews. 2020; 119: 66-85.

[30] Park JH, Son YD, Kim Y, Han DH. Brain Network Connectivity and Association with Catechol-O-Methyltransferase Gene Polymorphism in Korean Attention-Deficit Hyperactivity Disorder Children. Psychiatry Investigation. 2020; 17: 925-933.

[31] de Manzano O, Cervenka S, Karabanov A, Farde L, Ullén F. Thinking outside a less intact box: thalamic dopamine D2 receptor densities are negatively related to psychometric creativity in healthy individuals. PLoS ONE. 2010; 5: e10670.

[32] Boot N, Baas M, van Gaal S, Cools R, De Dreu CKW. Creative cognition and dopaminergic modulation of fronto-striatal networks: Integrative review and research agenda. Neuroscience and Biobehavioral Reviews. 2017; 78: 13-23. 
[33] Lauring JO, Ishizu T, Kutlikova HH, Dörflinger F, Haugbøl S, Leder H, et al. Why would Parkinson's disease lead to sudden changes in creativity, motivation, or style with visual art?: a review of case evidence and new neurobiological, contextual, and genetic hypotheses. Neuroscience and Biobehavioral Reviews. 2019; 100: 129-165.

[34] Reuter M, Roth S, Holve K, Hennig J. Identification of first candidate genes for creativity: a pilot study. Brain Research. 2006; 1069: 190-197.

[35] Takeuchi H, Tomita H, Taki Y, Kikuchi Y, Ono C, Yu Z, et al. The associations among the dopamine $\mathrm{D} 2$ receptor Taq1, emotional intelligence, creative potential measured by divergent thinking, and motivational state and these associations' sex differences. Frontiers in Psychology. 2015; 6: 912.

[36] Mayseless N, Uzefovsky F, Shalev I, Ebstein RP, Shamay-Tsoory SG. The association between creativity and $7 \mathrm{R}$ polymorphism in the dopamine receptor D4 gene (DRD4). Frontiers in Human Neuroscience. 2013; 7: 502.

[37] Jiang W, Shang S, Su Y. Genetic influences on insight problem solving: the role of catechol-O-methyltransferase (COMT) gene polymorphisms. Frontiers in Psychology. 2015; 6: 1569.

[38] Volf NV, Kulikov AV, Bortsov CU, Popova NK. Association of verbal and figural creative achievement with polymorphism in the human serotonin transporter gene. Neuroscience Letters. 2009; 463: 154-157.

[39] Schmechel DE, Edwards CL. Fibromyalgia, mood disorders, and intense creative energy: a1 at polymorphisms are not always silent. Neurotoxicology. 2012; 33: 1454-1472.

[40] Schmechel DE. Art, alpha-1-antitrypsin polymorphisms and intense creative energy: blessing or curse? Neurotoxicology. 2007; 28: 899-914.

[41] Soeiro-de-Souza MG, Post RM, de Sousa ML, Missio G, do Prado $\mathrm{CM}$, Gattaz WF, et al. Does BDNF genotype influence creative output in bipolar i manic patients? Journal of Affective Disorders. 2012; 139: 181-186.

[42] De Dreu CKW, Baas M, Boot NC. Oxytocin enables novelty seeking and creative performance through upregulated approach: evidence and avenues for future research. Wiley Interdisciplinary Reviews: Cognitive Science. 2015; 6: 409-417.

[43] De Dreu CKW, Baas M, Roskes M, Sligte DJ, Ebstein RP, Chew $\mathrm{SH}$, et al. Oxytonergic circuitry sustains and enables creative cognition in humans. Social Cognitive and Affective Neuroscience. 2014; 9: 1159-1165.

[44] Liu Z, Zhang J, Xie X, Rolls ET, Sun J, Zhang K, et al. Neural and genetic determinants of creativity. NeuroImage. 2018; 174: 164176.

[45] Li H, Zhang C, Cai X, Wang L, Luo F, Ma Y, et al. Genomewide Association Study of Creativity Reveals Genetic Overlap with Psychiatric Disorders, Risk Tolerance, and Risky Behaviors. Schizophrenia Bulletin. 2020; 46: 1317-1326.

[46] Kandler C, Riemann R, Angleitner A, Spinath FM, Borkenau P, Penke L. The nature of creativity: the roles of genetic factors, personality traits, cognitive abilities, and environmental sources. Journal of Personality and Social Psychology. 2016; 111: 230-249.

[47] Bachner-Melman R, Dina C, Zohar AH, Constantini N, Lerer E, Hoch S, et al. AVPR1a and SLC6a4 gene polymorphisms are associated with creative dance performance. PLoS Genetics. 2005; 1: e42.

[48] Pulli K, Karma K, Norio R, Sistonen P, Göring HHH, Järvelä I. Genome-wide linkage scan for loci of musical aptitude in Finnish families: evidence for a major locus at 4q22. Journal of Medical Genetics. 2008; 45: 451-456.

[49] Theusch E, Basu A, Gitschier J. Genome-wide Study of Families with Absolute Pitch Reveals Linkage to 8q24.21 and Locus Heterogeneity. The American Journal of Human Genetics. 2009; 85: 112-119.

[50] Ukkola LT, Onkamo P, Raijas P, Karma K, Järvelä I. Musical aptitude is associated with AVPR1A-haplotypes. PLoS ONE. 2009; 4: e5534.

[51] Ukkola-Vuoti L, Oikkonen J, Onkamo P, Karma K, Raijas P, Järvelä I. Association of the arginine vasopressin receptor $1 \mathrm{a}$ (AVPR1a) haplotypes with listening to music. Journal of Human Genetics. 2011; 56: 324-329.

[52] Park H, Lee S, Kim H, Ju YS, Shin J, Hong D, et al. Comprehensive genomic analyses associate UGT8 variants with musical ability in a Mongolian population. Journal of Medical Genetics. 2012; 49: 747-752.

[53] Morley AP, Narayanan M, Mines R, Molokhia A, Baxter S, Craig $\mathrm{G}$, et al. AVPR1a and SLC6a4 polymorphisms in choral singers and non-musicians: a gene association study. PLoS ONE. 2012; 7: e31763.

[54] Ukkola-Vuoti L, Kanduri C, Oikkonen J, Buck G, Blancher C, Raijas $\mathrm{P}$, et al. Genome-wide copy number variation analysis in extended families and unrelated individuals characterized for musical aptitude and creativity in music. PLoS ONE. 2013; 8: e56356.

[55] Oikkonen J, Huang Y, Onkamo P, Ukkola-Vuoti L, Raijas P, Karma $\mathrm{K}$, et al. A genome-wide linkage and association study of musical aptitude identifies loci containing genes related to inner ear development and neurocognitive functions. Molecular Psychiatry. 2015; 20: 275-282.

[56] Oikkonen J, Kuusi T, Peltonen P, Raijas P, Ukkola-Vuoti L, Karma $\mathrm{K}$, et al. Creative Activities in Music-a Genome-Wide Linkage Analysis. PLoS ONE. 2016; 11: e0148679.

[57] Beversdorf DQ, Carpenter AL, Alexander JK, Jenkins NT, Tilley MR, White CA, et al. Influence of Serotonin Transporter SLC6a 4 Genotype on the Effect of Psychosocial Stress on Cognitive Performance: an Exploratory Pilot Study. Cognitive and Behavioral Neurology. 2018; 31: 79-85.

[58] Müllensiefen D, Gingras B, Musil J, Stewart L. The musicality of non-musicians: an index for assessing musical sophistication in the general population. PLoS ONE. 2014; 9: e89642.

[59] Hannon EE, Trainor LJ. Music acquisition: effects of enculturation and formal training on development. Trends in Cognitive Sciences. 2007; 11: 466-472.

[60] Peretz I. The nature of music from a biological perspective. Cognition. 2006; 100: 1-32.

[61] Tan YT, McPherson GE, Peretz I, Berkovic SF, Wilson SJ. The genetic basis of music ability. Frontiers in Psychology. 2014; 5: 658

[62] Peretz I, Cummings S, Dubé MP. The genetics of congenital amusia (tone deafness): a family-aggregation study. American Journal of Human Genetics. 2007; 81: 582-588.

[63] Drayna D, Manichaikul A, de Lange M, Snieder H, Spector T. Genetic correlates of musical pitch recognition in humans. Science. 2001; 291: 1969-1972.

[64] Theusch E, Gitschier J. Absolute pitch twin study and segregation analysis. Twin Research and Human Genetics. 2011; 14: 173-178.

[65] Gregersen PK, Kowalsky E, Lee A, Baron-Cohen S, Fisher SE, Asher JE, et al. Absolute pitch exhibits phenotypic and genetic overlap with synesthesia. Human Molecular Genetics. 2013; 22: 2097-2104.

[66] Limb CJ, Braun AR. Neural substrates of spontaneous musical performance: an FMRI study of jazz improvisation. PLoS ONE. 2008; 3: e1679.

[67] Granot RY, Frankel Y, Gritsenko V, Lerer E, Gritsenko I, Bachner-Melman R, et al. Provisional evidence that the arginine vasopressin 1a receptor gene is associated with musical memory. Evolution and Human Behavior. 2007; 28: 313-318.

[68] Granot RY, Uzefovsky F, Bogopolsky H, Ebstein RP. Effects of arginine vasopressin on musical working memory. Frontiers in Psychology. 2013; 4: 712.

[69] Gingras B, Honing H, Peretz I, Trainor LJ, Fisher SE. Defining the biological bases of individual differences in musicality. Philosophical Transactions of the Royal Society B: Biological Sciences. 2015; 370: 20140092.

[70] Levitin DJ. What does it mean to be musical? Neuron. 2012; 73: 633-637. 
[71] Shigihara Y, Zeki S. Parallel processing in the brain's visual form system: an fMRI study. Frontiers in Human Neuroscience. 2014; 8: 506.

[72] Zeki S. Multiple asynchronous stimulus- and task-dependent hierarchies (STDH) within the visual brain's parallel processing systems. The European Journal of Neuroscience. 2016; 44: 25152527.

[73] Brang D, Ramachandran VS. Survival of the synesthesia gene: why do people hear colors and taste words? PLoS Biology. 2011; 9: e1001205.

[74] Simner J, Mulvenna C, Sagiv N, Tsakanikos E, Witherby SA, Fraser C, et al. Synaesthesia: the Prevalence of Atypical CrossModal Experiences. Perception. 2006; 35: 1024-1033.

[75] Rothen N, Meier B. Higher prevalence of synaesthesia in art students. Perception. 2010; 39: 718-720.

[76] Asher JE, Lamb JA, Brocklebank D, Cazier JB, Maestrini E, Addis L, et al. A whole-Genome Scan and Fine-Mapping Linkage Study of Auditory-Visual Synesthesia Reveals Evidence of Linkage to Chromosomes 2q24, 5q33, 6p12, and 12p12. The American Journal of Human Genetics. 2009; 84: 279-285.

[77] Tilot AK, Kucera KS, Vino A, Asher JE, Baron-Cohen S, Fisher SE. Rare variants in axonogenesis genes connect three families with sound-color synesthesia. Proceedings of the National Academy of Sciences of the United States of America. 2018; 115: 3168-3173.

[78] Rouw R, Scholte HS. Increased structural connectivity in grapheme-color synesthesia. Nature Neuroscience. 2007; 10: 792797.

[79] Tilot AK, Vino A, Kucera KS, Carmichael DA, van den Heuvel L, den Hoed J, et al. Investigating genetic links between graphemecolour synaesthesia and neuropsychiatric traits. Philosophical Transactions of the Royal Society B: Biological Sciences. 2019; 374: 20190026.
[80] Hughes JEA, Simner J, Baron-Cohen S, Treffert DA, Ward J Is Synaesthesia more Prevalent in Autism Spectrum Conditions? only where there is Prodigious Talent. Multisensory Research. 2017; 30: 391-408.

[81] Snyder AW, Mulcahy E, Taylor JL, Mitchell DJ, Sachdev P, Gandevia SC. Savant-like skills exposed in normal people by suppressing the left fronto-temporal lobe. Journal of Integrative Neuroscience. 2003; 2: 149-158.

[82] Rodenhauser P. Alternative reality and art: the creative world of Walter Inglis Anderson. Perspectives in Biology and Medicine. 2005; 48: 124-137.

[83] Thoburn R. Evolution of the Kunkel phenotype. Lupus. 2003; 12: 231-237.

[84] Si S, Su Y, Zhang S, Zhang J. Genetic susceptibility to parenting style: DRD2 and COMT influence creativity. NeuroImage. 2020; 213: 116681.

[85] Shumay E, Fowler JS, Volkow ND. Genomic features of the human dopamine transporter gene and its potential epigenetic States: implications for phenotypic diversity. PLoS ONE. 2010; 5: e11067.

[86] Champagne FA, Curley JP. Maternal regulation of estrogen receptor alpha methylation. Current Opinion in Pharmacology. 2008; 8: 735-739.

[87] Karlic H, Baurek P. Epigenetics and the power of art. Clinical Epigenetics. 2011; 2: 279-282.

[88] Gräff J, Mansuy IM. Epigenetic codes in cognition and behaviour. Behavioural Brain Research. 2008; 192: 70-87.

[89] Crutch SJ, Rossor MN. Artistic changes in Alzheimer's disease. International Review of Neurobiology. 2006; 74: 147-161.

[90] Jablonka E, Lamb MJ. Evolution in four dimensions, revised edition: Genetic, epigenetic, behavioral, and symbolic variation in the history of life. MIT press: USA. 2014. 